\title{
Currency Hedging Strategies Using Dynamic Multivariate GARCH*
}

\author{
Chia-Lin Chang \\ Department of Applied Economics \\ Department of Finance \\ National Chung Hsing University \\ Lydia González-Serrano \\ Department of Business Administration \\ Rey Juan Carlos University \\ Juan-Ángel Jiménez-Martín \\ Department of Quantitative Economics \\ Complutense University of Madrid
}

Revised: February 2012

* The authors are most grateful for the helpful comments and suggestions of Michael McAleer, Teodosio Perez Amaral, two referees, and participants at the International Conference on Risk Modelling and Management, Madrid, Spain, June 2011. The first author is most grateful for the financial support of the National Science Council, Taiwan, and the second author acknowledges the financial support of the Ministerio de Ciencia y Tecnología and Comunidad de Madrid, Spain. 


\begin{abstract}
This paper examines the effectiveness of using futures contracts as hedging instruments of: (1) alternative models of volatility for estimating conditional variances and covariances; (2) alternative currencies; and (3) alternative maturities of futures contracts. For this purpose, daily data of futures and spot exchange rates of three major international currencies, Euro, British pound and Japanese yen, against the American dollar, are used to analyze hedge ratios and hedging effectiveness resulting from using two different maturity currency contracts, near-month and next-to-near-month contract. Following Chang et al. [17], we estimate four multivariate volatility models (namely CCC, VARMA-AGARCH, DCC and BEKK), and calculate optimal portfolio weights and optimal hedge ratios to identify appropriate currency hedging strategies. The hedging effectiveness index suggests that the best results in terms of reducing the variance of the portfolio are for the USD/GBP exchange rate. The empirical results show that futures hedging strategies are slightly more effective when the near-month future contract is used for the USD/GBP and USD/JPY currencies. Moreover, the CCC and AGARCH models provide similar hedging effectiveness, which suggests that dynamic asymmetry may not be crucial empirically, although some differences appear when the DCC and BEKK models are used.
\end{abstract}

Keywords: Multivariate GARCH, conditional correlations, exchange rates, optimal hedge ratio, optimal portfolio weights, hedging strategies.

JEL Classifications: G32, G11, G17, C53, C22. 


\section{Introduction}

With increasing capital market liberalization and globalization, foreign currency denominated assets circulate rapidly throughout the world and, with increasing internationalization of financial transactions, the foreign exchange market has been profoundly transformed, and became more competitive and volatile. This places the accurate and reliable measurement of market risks in a critical position for both investment decision and hedging strategy designs.

Foreign exchange rate markets are the largest and most liquid of all asset markets. Developments in these markets influence national trade and monetary policies, and the competitiveness of nations. Foreign exchange markets are also important for the increasing number of companies engaged in cross-border trade and investment. Foreign exchange markets are naturally risky as they deal primarily in measuring, pricing, and managing risk. The success of an institution trading in the foreign exchange market depends critically on how well it assesses prices and manages the inherent risk, in its ability to limit losses from particular transactions, and to keep its overall exposure under control.

A key issue in managing currency risk is to control the volatility of the portfolio. The volatility of a portfolio includes variances and covariances of individual positions. Significant losses may arise from holding a portfolio without taking account of the timevarying variance and covariances. If investors can evaluate the interacting dynamics among markets in advance, then adjusting and hedging activities can usefully be implemented.

The aim of hedging is to use derivatives to reduce a particular risk. A relatively inexpensive and reliable strategy for hedging foreign exchange risk involves the use of foreign currency futures markets. Hedging with futures contracts is perhaps the simplest method for managing market risk arising from adverse movements in the foreign exchange market. Hedgers usually short an amount of futures contracts if they hold the long position of the underlying currency, and vice-versa. The question is how many futures contracts should be held for each unit of the underlying currency, as well as the effectiveness measure of that ratio. The hedge ratio provides information on how many 
futures contracts should be held, whereas its effectiveness evaluates the hedging performance and the usefulness of the strategy. In addition, hedgers may use the effectiveness measure to compare the benefits of hedging a given position from many alternative contracts.

In general, when the market trend is stable, the hedge ratio will become smaller, whereas if a big fluctuation of the market takes place, it will increase. Several distinct approaches have been developed to estimate the optimal hedge ratio (OHR), also known as the minimum-variance hedge ratio. The static hedging model with futures contracts (Johnson [32], Stein [56], Ederington, [21]) assumes that the joint distribution of spot and futures returns is time-invariant, so that the OHR, defined as the optimal number of futures holdings per unit of spot holdings, is constant over time. The minimum variance OHR use to be derived form the ordinary least squares (OLS) regression of spot price changes on future price changes. There is ample evidence that the simple OLS method is inappropriate to estimate hedge ratios as it suffers from the problem of serial correlation and heteroscedasticity often encountered in spot and futures price series (Herbst et al. [31]).

Therefore, the underlying assumption of the static hedging model of time-invariant asset distributions has been changed. The Autoregressive Conditional Heteroscedastic (ARCH) framework of Engle [23], and its extension to a generalized ARCH (GARCH) structure by Bollerslev [8], have proved to be very successful in modelling asset price second-moment movements. Bollerslev [9], Bailie and Bollerslev [3], and Diebold [19] have shown that the GARCH $(1,1)$ model is effective in explaining the distribution of exchange rate changes. However, Lien et al. [39] compared OLS and constantcorrelation vector generalized autoregressive conditional heteroscedasticity (VGARCH), and claimed that the OLS hedge ratio performs better than VGARCH. Chan [16] proposed a dynamic hedging strategy based on a bivariate GARCH jump model augmented with autoregressive jump intensity to manage currency risk. The collective evidence shows that GARCH-based dynamic hedging strategies are empirically appropriate, but the risk-reduction improvements over constant hedges vary across markets, and may also be sensitive to the sample period used. 
Regarding foreign currencies, different results seem to hold. Kroner and Sultan [35] demonstrated that GARCH hedge ratios produce better hedging effectiveness than conventional hedge ratios in currency markets. Chakraborty and Barkoulas [15] employed a bivariate GARCH model to estimate the joint distribution of spot and futures currency returns, and constructed a sequence of dynamic (time-varying) OHRs based on the estimated conditional covariances. The empirical evidence strongly supports time-varying OHRs, but the dynamic model provides superior out-of-sample hedging performance compared with the static model, but only for the Canadian dollar. $\mathrm{Ku}$ et al. [37] applied the dynamic conditional correlation (DCC) model of Engle [24] with error correction terms to investigate the optimal hedge ratios of British and Japanese currency futures markets, and compared the DCC and OLS estimates. The empirical results show that the DCC model yields the best hedging performance.

Given the distinct theoretical advantages of the dynamic hedging method over the static one, several papers have used the multivariate GARCH framework to examine the hedging performance for various assets. In order to evaluate the impact of model specification on the forecast of conditional correlations, Hakim and McAleer [29] analyze whether multivariate GARCH models incorporating volatility spillovers and asymmetric effects of negative and positive shocks on the conditional variance provide different conditional correlation forecasts. Using three multivariate GARCH models, namely CCC (Bollerslev, [10]), VARMA-GARCH (Ling and McAleer, [41]), and VARMA-AGARCH (McAleer et.al., [45]) they forecast conditional correlations between three classes of international financial assets (stocks, bonds and foreign exchange rates). They suggested that incorporating volatility spillovers and asymmetric effects of negative and positive shocks on the conditional variance does not affect the forecasts of conditional correlations.

In order to estimate time-varying hedge ratios using multivariate conditional volatility models, Chang et.al. [17] examined the performance of four models (namely CCC, VARMA-GARCH, DCC and BEKK) for the crude oil spot and futures returns of two major international crude oil markets (BRENT and WTI). The calculated OHRs from each multivariate conditional volatility model suggested time-varying hedge ratios, which recommended to short in crude oil futures, with a high portion of one dollar long 
in crude oil spot. The hedging effectiveness indicated that DCC (BEKK) was the best (worst) model for OHR calculation in terms of the variances of portfolio reduction.

This paper applies the Chang et al. [17] methods to currency hedging. In order to evaluate the impact of model specification on conditional correlations forecasts, this paper calculates and compares the correlations between conditional correlations forecasts arising from four different multivariate models (CCC, VARMA-AGARCH, DCC and BEKK) to estimate the returns on spot and futures (analyzing two sets of futures depending on their maturity) of three currency prices (USD/GBP, USD/EUR and USD/JPY). The purpose is to calculate the optimal portfolio weights and OHRs ratio from the conditional covariance matrices in order to achieve an optimal portfolio design and hedging strategy, and to compare the performance of OHRs from estimated multivariate conditional volatility models by applying the hedging effectiveness index. One of the main contributions of this paper is that it allows a comparison as to whether the results are different depending on the volatility model, currency and maturity of the futures contract selected.

The remainder of the paper is organized as follows. In Section 2 we discuss alternative multivariate GARCH models, and the derivation of the OHR and hedging effective index. In Section 3 the data used for estimation and forecasting, and the descriptive statistics, are presented. Section 4 analyses the empirical estimates, and Section 5 presents the conclusions.

\section{Econometric Models}

\subsection{Multivariate Conditional Volatility Models}

This paper closely follows Chang et.al. [17], who analysed dynamic crude oil hedging strategies, and considers the CCC model of Bollerslev [10], VARMA-AGARCH model of McAleer et al. [45], the DCC model of Engle [24], and BEKK model of Engle and Kroner [25] for alternative currencies. Constant conditional correlations are assumed in the first two models, while dynamic conditional correlations are specified in the last two models. 
Consider the CCC multivariate GARCH model of Bollerslev [10]:

$$
\begin{gathered}
y_{1}=E\left(y_{t} / F_{t-1}\right)+\varepsilon_{t}, \varepsilon_{t}=D_{t} \eta_{t} \\
\operatorname{var}\left(\varepsilon_{t} / F_{t-1}\right)=D_{t} \Gamma D_{t}
\end{gathered}
$$

where $y_{t}=\left(y_{1 t}, \ldots, y_{m t}\right)^{\prime}, \quad \eta_{t}=\left(\eta_{1 t}, \ldots, \eta_{m t}\right)^{\prime}$ is a sequence of independent and identically distributed random vectors, $F_{t}$ is the past information available at time $t$, $D_{t}=\operatorname{diag}\left(h_{1}^{1 / 2}, \ldots, h_{m}^{1 / 2}\right)$, and $m$ is the number of assets (see, for example, McAleer [43] and Bauwens et al. [6]). As $\Gamma=E\left(\eta_{t} \eta_{t}^{\prime} / F_{t-1}\right)=E\left(\eta_{t} \eta^{\prime}\right)$, where $\Gamma=\left\{\rho_{i j}\right\}$ for $i, j=1, \ldots$, $m$, the constant conditional correlation matrix of the unconditional shocks, $\eta_{t}$, is equivalent to the constant conditional covariance matrix of the conditional shocks, $\varepsilon_{t}$, from (1), $\varepsilon_{t} \varepsilon_{t}^{\prime}=D_{t} \eta_{t} \eta_{t}^{\prime} D_{t}, D_{t}=\left(\operatorname{diag} Q_{t}\right)^{1 / 2}$, and $E\left(\varepsilon_{t} \varepsilon_{t}^{\prime} / F_{t-1}\right)=Q_{t}=D_{t} \Gamma D_{t}$, where $Q_{t}$ is the conditional covariance matrix.

The CCC model of Bollerslev [10] assumes that the conditional variance for each return, $h_{i t}, i=1, \ldots, m$, follows a univariate GARCH process, that is

$$
h_{i t}=\omega_{i}+\sum_{j=1}^{r} \alpha_{i j} \varepsilon_{i, t-j}^{2}+\sum_{j=1}^{s} \beta_{i j} h_{i, t-j}
$$

where $\alpha_{i j}$ represents the ARCH effect, or short run persistence of shocks to return $i, \beta_{i j}$ represents the GARCH effect, and $\sum_{j=1}^{r} \alpha_{i j}+\sum_{j=1}^{s} \beta_{i j}$ denotes the long run persistence of the returns shocks.

The CCC model assumes that negative and positive shocks of equal magnitude have identical impacts on the conditional variance. McAleer et al. [45] extended the VARMA-GARCH model to accommodate the asymmetric impacts of the unconditional shocks on the conditional variance, and proposed the VARMA-AGARCH specification of the conditional variance as follows: 


$$
H_{t}=W+\sum_{i=1}^{r} A_{i} \vec{\varepsilon}_{t-i}+\sum_{i=1}^{r} C_{i} I_{t-i} \vec{\varepsilon}_{t-i}+\sum_{j=1}^{s} B_{j} H_{t-j}
$$

where $C_{i}$ are $m \times m$ matrices for $i=1, \ldots r$ with typical element $\gamma_{i j}$, and $I_{t}=\operatorname{diag}\left(I_{1 t}, \ldots, I_{m t}\right)$, is an indictor function, given as

$$
I\left(\eta_{i t}\right)=\left(\begin{array}{ll}
0, & \varepsilon_{i t}>0 \\
1, & \varepsilon_{i t} \leq 0
\end{array}\right)
$$

If $m=1$, (3) collapses to the asymmetric GARCH (or GJR) model of Glosten et al. [28]. If $C_{i}=0$ and $A_{i}$ and $B_{j}$ are diagonal matrices for all $i$ and $j$, then VARMA-AGARCH collapses to the CCC model. The structural and statistical properties of the model, including necessary and sufficient conditions for stationarity and ergodicity of VARMA-AGARCH, are explained in detail in McAleer et al. [45]. The parameters of model (1) to (3) are obtained by maximum likelihood estimation (MLE) using joint normal. We also estimate the models using the Student $t$ distribution, for which the appropriate estimator is QMLE.

The assumption that the conditional correlations are constant are not likely to be realistic so, in order to make the conditional correlation matrix time dependent, Engle [24] proposed a dynamic conditional correlation (DCC) model, which is defined as

$$
\begin{gathered}
y_{t} \mid \mathfrak{J}_{t-1} \sim\left(0, Q_{t}\right), t=1,2, \ldots, n \\
Q_{t}=D_{t} \Gamma_{t} D_{t},
\end{gathered}
$$

where $D_{t}=\operatorname{diag}\left(h_{1}^{1 / 2}, \ldots, h_{m}^{1 / 2}\right)$ is a diagonal matrix of conditional variances, and $\mathfrak{I}_{t}$ is the information set available at time $t$. The conditional variance, $h_{i t}$, can be defined as a univariate GARCH model, as follows:

$$
h_{i t}=\omega+\sum_{k=1}^{p} \alpha_{i k} \varepsilon_{i, t-k}+\sum_{l=1}^{q} \beta_{i l} h_{i, t-l}
$$


If $\eta_{t}$ is a vector of i.i.d. random variables, with zero mean and unit variance, $Q_{t}$ in (8) is the conditional covariance matrix (after standardization, $\eta_{i t}=y_{i t} / \sqrt{h_{i t}}$ ). The $\eta_{i t}$ are used to estimate the dynamic conditional correlations, as follows:

$$
\Gamma_{t}=\left\{( \operatorname { d i a g } ( Q _ { t } ) ^ { - 1 / 2 } \} Q _ { t } \left\{\left(\operatorname{diag}\left(Q_{t}\right)^{-1 / 2}\right\}\right.\right.
$$

where the $k \times k$ symmetric positive definitive matrix $Q_{t}$ is given by

$$
Q_{t}=\left(1-\theta_{1}-\theta_{2}\right) \bar{Q}+\theta_{1} \eta_{t-1} \eta_{t-1}^{\prime}+\theta_{2} Q_{t-1}
$$

in which $\theta_{1}$ and $\theta_{2}$ are scalar parameters to capture the effects of previous shocks and previous dynamic conditional correlations on the current dynamic conditional correlation, and $\theta_{1}$ and $\theta_{2}$ are non-negative scalar parameters. When $\theta_{1}=\theta_{2}=0, \bar{Q}$ in (9) is equivalent to CCC. As $Q_{t}$ is conditional on the vector of standardized residuals, (9) is a conditional covariance matrix, and $\bar{Q}$ is the $k \times k$ unconditional variance matrix of $\eta_{t}$. DCC is not linear, but may be estimated in EViews by using a two-step method based on the likelihood function, the first step being a series of univariate GARCH estimates and the second step being the correlation estimates.

An alternative dynamic conditional model is BEKK, which has the attractive property that the conditional covariance matrices are positive definite. However, BEKK suffers from the so-called "curse of dimensionality" (see McAleer et al. [45] for a comparison of the number of parameters in various multivariate conditional volatility models). The BEKK model for multivariate $\operatorname{GARCH}(1,1)$ is given as:

$$
H_{t}=C_{H}^{\prime} C_{H}^{\prime}+A^{\prime} \varepsilon_{t-1} \varepsilon_{t-1}^{\prime} A+B^{\prime} H_{t-1} B
$$

where the individual element for the matrices $C_{H}, A$ and $B$ matrices are given as

$$
A=\left(\begin{array}{ll}
a_{11} & a_{12} \\
a_{21} & a_{22}
\end{array}\right), B=\left(\begin{array}{ll}
b_{11} & b_{12} \\
b_{21} & b_{22}
\end{array}\right), C_{H}=\left(\begin{array}{ll}
c_{11} & c_{12} \\
c_{21} & c_{22}
\end{array}\right)
$$


The conditional variances are functions of their own lagged values and own lagged returns shocks, while the conditional covariances are functions of the lagged covariances and lagged cross-products of the corresponding returns shocks. The BEKK formulation guarantees $H_{t}$ to be positive definite almost surely for all $t$. A critical comparison between BEKK and DCC is given in Caporin and McAleer [12], where the scalar, diagonal and full versions of BEKK are also discussed.

\subsection{Optimal Hedge Ratios and Optimal Portfolio Weights}

Market participants in futures markets choose a hedging strategy that reflects their attitudes toward risk and their individual goals. Adapting the crude oil hedging strategies discussed in Chang et al. [17] for currencies, consider the case of exchange rates, where the return on the portfolio of spot and futures position can be denoted as:

$$
R_{H, t}=R_{S, t}-\gamma R_{F, t}
$$

In equation (11), $R_{H, t}$ is the return on holding the portfolio between $t-1$ and $t, R_{S, t}$ and $R_{F, t}$ are the returns on holding spot and futures positions between $t$ and $t-1$, and $\gamma$ is the hedge ratio, that is, the number of futures contracts that the hedger must sell for each unit of spot commodity on which price risk is borne.

According to Johnson [32], the variance of the returns of the hedged portfolio, conditional on the information set available at time $t-1$ is given by

$$
\operatorname{var}\left(R_{H, t} \mid \Omega_{t-1}\right)=\operatorname{var}\left(R_{S, t} \mid \Omega_{t-1}\right)-2 \gamma \operatorname{cov}\left(R_{S, t}, R_{F, t} \mid \Omega_{t-1}\right)+\gamma_{t}^{2} \operatorname{var}\left(R_{F, t} \mid \Omega_{t-1}\right)
$$

where $\operatorname{var}\left(R_{S, t} \mid \Omega_{t-1}\right), \operatorname{var}\left(R_{F, t} \mid \Omega_{t-1}\right), \quad$ and $\operatorname{cov}\left(R_{S, t}, R_{F, t} \mid \Omega_{t-1}\right)$ are the conditional variance and covariance of the spot and futures returns, respectively. The OHRs are defined as the value of $\gamma_{\mathrm{t}}$ which minimizes the conditional variance (risk) of the hedged portfolio returns, that is $\min _{\gamma_{t}}\left[\operatorname{var}\left(R_{H, t} \mid \Omega_{t-1}\right)\right]$. Taking the partial derivate of (12) with respect to $\gamma_{t}$, setting it to zero, and solving for $\gamma_{t}$, yields the $\mathrm{OHR}_{\mathrm{t}}$ conditional on the information available at $t-1$ (see, for example, Baillie and Myers [4]): 


$$
\gamma_{t}^{*} \mid \Omega_{t-1}=\frac{\operatorname{cov}\left(R_{S, t}, R_{F, t} \mid \Omega_{t-1}\right)}{\operatorname{var}\left(R_{F, t} \mid \Omega_{t-1}\right)}
$$

where returns are defined as the logarithmic differences of spot and futures prices.

From the multivariate conditional volatility model, the conditional covariance matrix is obtained, such that the OHR is given as:

$$
\gamma_{t}^{*} \mid \Omega_{t-1}=\frac{h_{S F, t}}{h_{F, t}},
$$

where $h_{S F, t}$ is the conditional covariance between spot and futures returns, and $h_{F, t}$ is the conditional variance of futures returns.

In order to compare the performance of OHRs obtained from different multivariate conditional volatility models, $\mathrm{Ku}$ et al. [37] suggest that a more accurate model of conditional volatility should also be superior in terms of hedging effectiveness, as measured by the variance reduction for any hedged portfolio compared with the unhedged portfolio. Thus, a hedging effective index (HE) is given as:

$$
H E=\left[\frac{\mathrm{var}_{\text {unhedged }}-\mathrm{var}_{\text {hedged }}}{\mathrm{var}_{\text {unhedged }}}\right],
$$

where the variances of the hedge portfolio are obtained from the variance of the rate of return, $R_{H, t}$, and the variance of the unhedged portfolio is the variance of spot returns (see, for example, Ripple and Moosa [50]). A higher HE indicates a higher hedging effectiveness and larger risk reduction, such that hedging method with a higher HE is regarded as a superior hedging strategy.

Alternatively, in order to construct an optimal portfolio design that minimizes risk without lowering expected returns, and applying the methods of Kroner and $\mathrm{Ng}$ [33] and Hammoudeh et al. [30], the optimal portfolio weight of exchange rate spot/futures holding is given by: 


$$
w_{S F, t}=\frac{h_{F, t}-h_{S F, t}}{h_{S, t}-2 h_{S F, t}+h_{F, t}}
$$

and

$$
w_{S F, t}^{*}=\left\{\begin{array}{cc}
0, & \text { if } \mathrm{w}_{\mathrm{SF}, \mathrm{t}}<0 \\
w_{S F, t}, & \text { if } 0<\mathrm{W}_{\mathrm{SF}, \mathrm{t}}<1 \\
1, & \text { if } \mathrm{w}_{\mathrm{SF}, \mathrm{t}}>1
\end{array}\right.
$$

where $\mathrm{w}_{\mathrm{SF}, \mathrm{t}}^{*}\left(1-\mathrm{w}_{\mathrm{SF}, \mathrm{t}}\right)$ is the weight of the spot (futures) in a one dollar portfolio of exchange rates spot/futures at time $t$.

\section{Data}

We used daily closing prices of spot $(\mathrm{S})$ and futures for three major international foreign exchange rate series, the value of the US dollar to one European Euro (USD/EUR), one British Pound (USD/GBP), or one Japanese Yen (USD/JPY). Futures prices rather than forward prices are used because of the higher data frequency of the former and also because futures data represent two different maturity currency contracts, namely nearmonth and next-to-near-month contracts.

The 3,006 observations from 3 January 2000 to 11 July 2011 are obtained from the Thomson Reuters-Ecowin Financial Database. The perpetual series of futures prices derived from individual futures contracts. These contracts call for a delivery of a specified quantity of a specified currency, or a cash settlement, during the months of March, June, September and December (the "March quarterly cycle"). Selected contracts are available with two future position continuous series. The futures price series for First Position Future (FUT1) is the price of the near-month delivery contract and the Second Position Future (FUT2) is the price of the next-to-near-month delivery contract. For example, in 1 February 2011, FUT 1 is the price of the contract that expires in March 2011, while FUT 2 is the price of the contract that expires in June 2011. 


\section{[Insert Tables 1-3]}

The returns of currency $i$ at time $t$ are calculated as $r_{i, t}=\log \left(P_{i, t} / P_{i, t-1}\right)$, where $\mathrm{P}_{i, t}$ and $\mathrm{P}_{i, t-1}$ are the closing prices of currency $i$ for days $t$ and $t-1$ respectively. In Tables 1,2 and 3 we show the descriptive statistics for the return series of EUR, GBP and JPY. The mean is close to zero in all cases. For the EUR and JPY currencies the standard deviation of the futures returns is larger than that of the spot returns, indicating the futures market is more volatile than the spot market for these currencies. The exchange rate return series display high kurtosis and heavy tails. Most of them, except EUR, present negative skewness statistics that signify increased presence of extreme losses than extreme gains (longer left tails). The Jarque-Bera Lagrange Multiplier test rejects the null hypothesis of normally distributed returns for every exchange rate series.

\section{[Insert Figure 1]}

Figure 1 presents the plot of spot and futures daily returns for each currency. Extremely high positive and negative returns are evident from September 2008 onward, and have continued well into 2009. Therefore, an increase in volatility during the financial crisis is perceived, however, is lower than in other assets (see, for example, McAleer et al. [46]). In the same way, the plots indicate volatility clustering. Spot and futures returns move in the same pattern suggesting a high correlation (the highest one is between FUT1 and FUT2 for all currencies). Correlations between the returns in European markets (EUR and GBP) are higher than the correlations between these and JPY which is hardly surprising.

\section{[Insert Figure 2]}

The volatilities of exchange rate returns are showed in figure 2 . These volatilities are calculated as the square of the estimated returns and seem to support the stated above. The plots are similar in all returns and the volatility of the series appears to be high during the early 2000s, followed by a quiet period from 2003 to the beginning of 2007. 
Volatility increases dramatically after August 2008, due in large part to the worsening global credit environment.

\section{4.- Empirical Results}

\subsection{Estimation Results}

We estimate four multivariate models (namely CCC, VARMA-AGARCH, DCC and BEKK) for each error distribution, currency and different futures maturities. The estimated parameters are reported in Tables 4-7. Table 4 shows the estimates for the CCC model. The volatility persistence, as measure by the sum of $\alpha+\beta$, in either spot or futures markets for each currency is quite high, ranging from 0.978 to 0.998 . All markets satisfy the second moment and log moment condition, which is a sufficient condition for the QMLE to be consistent and asymptotically normal (see McAleer et.al. [44]) The ARCH and GARCH estimates of the conditional variance are statistically significant. The ARCH estimates are generally small (less than 0.04) and the GARCH effects are generally close to one. The estimates are generally smaller for JPY for both spot and futures prices (0.949 and 0.944 against 0.961 and 0.962 for the EUR). There are not large differences among the constant conditional correlation estimates, ranging from 0.799 for EUR to 0.811 for JPY.

\section{[Insert Tables 4-5]}

Table 5 reports the estimates of the conditional means and variances for the AGARCH models. The ARCH and GARCH effects are statistically significant in all markets, and are quite similar to the estimates for the CCC model without asymmetric effects. The asymmetric impacts of the unconditional shocks on the conditional variance estimates, $\gamma$, are reasonably weak for the three currencies and, in particular, are not statistically significant for JPY.

\section{[Insert Table 6]}


The DCC model is used to capture dynamic conditional correlations. Table 6 summaries the results of the DCC estimates for all spot and futures markets. Regarding the conditional variance, the estimates are statistically significant and satisfy the second moment condition. The estimated DCC parameters, $\hat{\theta}_{1}$ and $\hat{\theta}_{2}$, are statistically significant for all currencies, which suggests that the conditional correlations are not constant over time. The short run persistence of shocks on the dynamic conditional correlation is greater for JPY at 0.051 , although it shows the lower long run persistence of shocks to the conditional correlation $0.913(0.051+0.862)$. The EUR shows the lowest short run persistence (0.024) and the greatest long run persistence 0.986 $(0.024+0.962)$. The time-varying conditional correlations between spot and futures returns are given in Figure 3. An apparent change in the conditional correlation appeared upon the bankruptcy of Lehman Brothers in New York on 15 September 2008. Due to an increase in the volatility of spot and futures exchange rates, the conditional correlations seem to change in all the currencies. The GFC caused an apparent decline in the conditional correlations between spot prices and both FUT1 an FUT2.

\section{[Insert Table 7]}

Table 7 reports the estimates for the BEKK model. We have restricted the bivariate BEKK model to the reduced form of the diagonal BEKK. The elements of the covariance matrix depend only on past own squared residuals, and the covariances depend only on past own cross products of residuals. The estimates of mean returns are not statistically significant. The elements of the diagonal matrices, A and B, are statistically significant. From the empirical results, we conclude there is time-varying market risk, strong evidence of GARCH effects, and the presence of weak ARCH effects. The results for the covariances are similar, indicating that there is a statistically significant time-varying covariation in shocks, which depends more on own lags than on past innovations. These empirical results show that market shocks are influenced by information which is common to spot and future markets.

\subsection{Hedging Performance}


With the estimated underlying parameters in the models, we first generate in-sample daily time series of variances and covariances of the spot and futures returns for each currency. Subsequently, we calculate the OHRs and optimal portfolios weights given by equations (14) and (16), respectively.

\section{[Insert Table 8A-8C]}

Tables $8 \mathrm{~A}-8 \mathrm{C}$ report the average OHR values, the hedge effectiveness, the variance of the portfolio, the hedging effectiveness along with the average value of the optimal portfolio weights for the three currencies using FUT1 and FUT2 contracts when both the Student $t$ and normal error distributions are assumed. We show the results for the four multivariate volatility models.

Tables $8 \mathrm{~A}-8 \mathrm{C}$ show that hedging is effective in reducing the risks for every model, currency and maturity. In particular, we find that the average OHR using FUT2 contracts are slightly higher than when FUT1 contracts are used, except for GBP. The highest average OHR value is 0.854 for USD/JPY when FUT2 contracts are used, meaning that, in order to minimize risk, a long (buy) position of one dollar in such a currency should be hedged by a short (sell) position of \$0.854 in JPYFUT2 contracts. Additionally, when using the Gaussian error distribution, Tables 8A-8C report lower average OHR values for the three currencies analyzed. The average OHRs from each model are not particularly different, slightly smaller for the DCC and BEKK models when the Student $\mathrm{t}$ is used, but larger for GBP and JPY when using the Gaussian distribution. The average OHR values are higher for the USD/JPY exchange rate. On the contrary, hedging effectiveness is higher for the DCC and BEKK models.

For GBP and JPY, we notice that hedging effectiveness is slightly higher when a FUT1 contract is used, as opposed to showing a higher hedging effectiveness when the EURFUT2 contract is used. We find that hedging effectiveness lies between a maximum of $66.3 \%$ for USD/GBP, and a minimum of $62.5 \%$ for USD/EUR. It seems that hedging effectiveness is slightly higher for the USD/GBP currency.

[Insert Figures 3-4] 
Figure 3 shows the DCC estimates between spot and futures exchange rates for both future contracts. The volatility of the dynamic correlations increases during GFC and, as expected, during turbulent periods correlations decreases. This is why OHR volatility increases during the GFC. Figure 4 represents the calculated time-varying OHRs from every multivariate conditional volatility model. There are clearly time-varying ratios. It is interesting to examine the optimal hedging ratios during the GFC for all the models, but DCC optimal hedging ratios seem to increase in average.

As shown in the optimal portfolio weight columns in Tables $8 \mathrm{~A}-8 \mathrm{C}$, there are not big differences among the models. For example, the largest average value corresponds to a portfolio including the JPYFUT1 contract, for which the spot currency weight is calculated using the DCC model assuming a normal error distribution. The value 0.566 would imply that investors should have more spot currency than futures contracts in their portfolio in order to minimize risk without lowering expected returns. In particular, the optimal holding of one USD/JPY spot/future portfolio is 56.6 cents for spot and 43.4 cents for futures. When the Gaussian distribution is used, we find higher optimal portfolio weights. For both USD/EUR and USD/JPY spot/futures portfolios the optimal holding of spot currencies is higher when hedging with FUT1 contracts than when FUT2 are used. This is the opposite of what happens for USD/GBP spot/futures portfolios. The estimates suggest holding spot more than GBPFUT1, whereas they suggest holding spot less than GBPFUT2 on one dollar spot/future portfolio.

\section{[Insert Table 9A-9C]}

The correlations of the dynamic patterns in Tables $8 \mathrm{~A}-8 \mathrm{C}$ are given in Tables 9A-9C. It is clear that, across all currencies and both error densities, the OHRs are most similar between CCC and VARMA-AGARCH, which suggests that dynamic asymmetry may not be crucial empirically, and also between DCC and BEKK.

In summary, the estimates based on both OHR and optimal weight values recommend holding more FUT2 than FUT1 contracts for USD/EUR and USD/JPY spot/futures portfolios, meaning that we should increase the percentage of futures contracts for longer term portfolios when these currencies are used. 


\section{Conclusions}

This paper sheds light on the importance of measuring conditional variances and covariances when hedging daily currency risk using futures. The findings are of importance to currency hedgers who require taking futures positions in order to adequately reduce the risk. In this paper, we use four multivariate GARCH models, namely CCC, VARMA-AGARCH, DCC and BEKK, to examine the conditional volatilities among spot and two distinct futures maturities, namely near-month and nextto-near-month contracts. The estimated conditional covariances matrices from these models were used to calculate the optimal portfolios weights and optimal hedge ratios.

The empirical results in this paper reveal that there are not big effectiveness differences when either the near-moth or the next-to-near-month contract is used for hedging spot position on currencies. They also reveal that hedging ratios are lower for near-month contract when the USD/EUR and USD/JPY exchange rates are analyzed. This result is explained in terms of the higher correlation between spot prices and the next-to-nearmonth futures prices than that with near-month contract and additionally because of the lower volatility of the long maturity futures.

Finally, across all currencies and error densities, the CCC and VARMA-AGARCH models provide similar results in terms of hedging ratios, portfolio variance reduction and hedging effectiveness, which suggests that dynamic asymmetry may not be crucial empirically. Some differences appear when the DCC and BEKK models are used. Hedging ratios seem to decrease during the GFC as opposed to increasing ratios when the CCC and VARMA-AGARH models are consider for calculating the conditional covariances. Future research will investigate the effects of the GFC on the conditional correlations between spot and futures contracts, as well as its impact on hedging effectiveness. 


\section{References}

[1] P. Araújo Santos, M.I. Fraga Alves, A new class of independence tests for interval forecasts evaluation, Computational Statistics and Data Analysis (2010) in press, doi:10.1016/j.csda2010.10.002.

[2] P. Araújo Santos, Interval forecasts evaluation: R programs for a new independence test, Notas e Comunicações CEAUL 17/2010.

[3] R. T. Baillie, T. Bollerslev, The message in daily exchange rates: a conditionalvariance tale, Journal of Business and Economic Statistics, 7 (1989) 295-307.

[4] R. T. Baillie, R.J Myers, Bivariate GARCH estimation of the optimal commodity futures hedge, Journal of Applied Econometrics, 6 (1991) 109-124.

[5] A. A. Balkema, L. de Haan, Residual life time at great age, Annals of Probability, 2 (1974) 792-804.

[6] L. Bauwens, S. Laurent, J. Rombouts, Multivariate GARCH models: A survey, Journal of Applied Economics, 21 (2006) 79-109.

[7] F. Black, Studies of stock market volatility changes, 1976 Proceedings of the American Statistical Association, Business and Economic Statistics Section, 177181.

[8] T. Bollerslev, Generalised autoregressive conditional heteroscedasticity, Journal of Econometrics, 31 (1986) 307-327.

[9] T. Bollerslev, A conditional heteroscedastic time series model for speculative prices and rates of return, Review of Economics and Statistics, 69 (1987) 542-547.

[10] T. Bollerslev, Modelling the coherence in short-run nominal exchange rates: a multivariate generalized ARCH model, Review of Economics and Statistics, 72 (1990) 498-505.

[11] H. Bystrom, Managing extreme risks in tranquil and volatile markets using conditional extreme value theory, International Review of Financial Analysis, 13 (2) (2004) 133-152.

[12] M. Caporin, M. McAleer, Scalar BEKK and indirect DCC, Journal of Forecasting, 27 (2008) 537-549.

[13] M. Caporin, M. McAleer, The Ten Commandments for managing investments, Journal of Economic Surveys, 24 (2010a) 196-200. 
[14] M. Caporin, M. McAleer, to appear in L. Bauwens, C. Hafner and S. Laurent (eds.), Model selection and testing of conditional and stochastic volatility models, Handbook on Financial Engineering and Econometrics: Volatility Models and Their Applications, Wiley, New York, (2010b), pp. 199-222 (Available at SSRN: http://ssrn.com/abstract=1676826).

[15] A. Chakraborty, J.T. Barkoulas, Dynamic futures hedging in currency markets, The European Journal of Finance, 5 (1999) 299-314.

[16] W.H. Chan, Dynamic Hedging with Foreign Currency Futures in the Presence of Jumps, Studies in Nonlinear Dynamics \& Econometrics, V. 12, Issue 2 (2008) 124.

[17] C.-L. Chang, M. McAleer, R. Tansuchat, Crude oil hedging strategies using dynamic multivariate GARCH, Energy Economics, 33(5) (2011) 912-923.

[18] P. Christoffersen P., Evaluating intervals forecasts, International Economic Review, 39 (1998) 841-862.

[19] F.X. Diebold, Empirical Modeling of Exchange Rate Dynamics, Springer Verlag, New York, 1988.

[20] F.X. Diebold, T. Schuermann, J.D. Stroughair, Pitfalls and opportunities in the use of extreme value theory in risk Management, Working Paper, (1998) 98-10, Wharton School, University of Pennsylvania.

[21] L.H. Ederington, The hedging performance of the new futures markets, Journal of Finance, 34 (1979) 157-170.

[22] P. Embrechts, C. Klüppelberg, T. Mikosch, Modeling extremal events for insurance and finance, Springer, Berlín, 1997.

[23] R.F. Engle, Autoregressive conditional heteroscedasticity with estimates of the variance of United Kingdom inflation, Econometrica, 50 (1982) 987-1007.

[24] R.F. Engle, Dynamic conditional correlation: A simple class of multivariate generalized autoregressive conditional heteroskedasticity models, Journal of Business and Economic Statistics, 20 (2002) 339-350.

[25] R.F. Engle., K.F. Kroner, Multivariate simultaneous generalized ARCH, Econometric Theory, 11 (1995) 122-150.

[26] P.H. Franses, D. van Dijk, Nonlinear Time Series Models in Empirical Finance, Cambridge University Press, Cambridge, 1999.

[27] R. Giacomini, I. Komunjer, Evaluation and combination of conditional quantile forecasts, Journal of Business \& Economic Statistics, 23 (2005) 416-431. 
[28] L. Glosten, R. Jagannathan, D. Runkle, On the relation between the expected value and volatility of nominal excess return on stocks, Journal of Finance, 46 (1992) 1779-1801.

[29] A. Hakim, M. McAleer, Forecasting conditional correlations in stock, bond and foreign exchange markets, Mathematics and Computers in Simulation, 79 (2009) 2830-2846.

[30] S. Haqmmoudeh, Y. Yuan, M. McAleer, M.A. Thomson, M.A., Precious metalsexchange rate volatility transmissions and hedging strategies, International Review of Economics and Finance, 19 (2010) 633-647.

[31] A.F. Herbs, D.D. Kare, J.F. Marshall, A time varying convergence adjusted, minimum risk futures hedge ratio, Advances in futures and option research, vol. 6 April (1993) 137-155.

[32] L.L. Johnson, The theory of hedging and speculation in commodity futures, Review of Economic Studies, 27 (1960) 139-151.

[33] K.F. Kroner, V. Ng, Modelling asymmetric movements of asset prices, Review of Financial Studies, 11 (1998) 844-871.

[34] K.F. Kroner, J. Sultan, in S.G. Rhee and R.P. Change (eds.), Foreign currency futures and time varying hedge ratios, Pacific-Basin Capital Markets Research, Vol. II, Amsterdam North-Holland, pp. 397-412, 1991.

[35] K.F. Kroner, J. Sultan, Time-varying distributions and dynamic hedging with foreign currency futures, Journal of Financial and Quantitative Analysis, 28 (1993) 535-551.

[36] P. Kupiec, Techniques for verifying the accuracy of risk measurement models, Journal of Derivatives, 3 (1995) 73-84.

[37] Y.H. Ku, H.C. Chen, K.H. Chen, (2007), On the application of the dynamic conditional correlation model in estimating optimal time-varying hedge ratios, Applied Economics Letters, 14 (2007) 503-509.

[38] W.K. Li, S. Ling, M. McAleer, M., Recent theoretical results for time series models with GARCH errors, Journal of Economic Surveys, 16 (2002) 245-269. Reprinted in M. McAleer and L. Oxley (eds.), Contributions to Financial Econometrics: Theoretical and Practical Issues, Blackwell, Oxford, pp. 9-33.

[39] D. Lien, Y.K. Tse, A.K. Tsui, Evaluating the hedging performance of the constantcorrelation GARCH model, Applied Financial Economics, 12 (2002) 791-798. 
[40] S. Ling, M. McAleer, Stationarity and the existence of moments of a family of GARCH processes, Journal of Econometrics, 1061 (2002a) 9-117.

[41] S. Ling, M. McAleer, Necessary and sufficient moment conditions for the $\operatorname{GARCH}(\mathrm{r}, \mathrm{s})$ and asymmetric power $\operatorname{GARCH}(\mathrm{r}, \mathrm{s})$ models, Econometric Theory, 18 (2002b) 722-729.

[42] S. Ling, M. McAleer, Asymptotic theory for a vector ARMA-GARCH model, Econometric Theory, 19 (2003) 278-308.

[43] M. McAleer, Automated inference and learning in modelling financial volatility, Econometric Theory, 21 (2005) 232-261.

[44] M. McAleer, F. Chan, F., D. Marinova, An econometric analysis of asymmetric volatility: theory and application to patents, Journal of Econometrics, 139 (2007) 259-284.

[45] M. McAleer, S. Hoti, F. Chan, Structure and asymptotic theory for multivariate asymmetric conditional volatility, Econometric Reviews, 28 (2009) 422-440.

[46] M. McAleer, J.A. Jiménez-Martín, T. Pérez- Amaral, T., International Evidence on GFC-robust Forecasts for Risk Management under the Basel Accord, to appear in Journal of Forecasting, 2011 (Available at SSRN: http://papers.ssrn.com/sol3/papers.cfm?abstract_id=1741565)

[47] A.J. McNeil, R. Frey, Estimation of tail-related risk measures for heteroscedastic financial time series: An extreme value approach, Journal of Empirical Finance, 7 (2000) 271-300.

[48] D.B. Nelson, Conditional heteroscedasticity in asset returns: A new approach, Econometrica, 59 (1991) 347-370.

[49] J. Pickands III, Statistical inference using extreme value order statistics, Annals of Statistics, 3 (1975) 119-131.

[50] R.D. Ripple, I.A. Moosa, Hedging effectiveness and futures contract maturity: the case of NYMEX crude oil futures, Applied Financial Economics, 17 (2007) 683689.

[51] Riskmetrics, J.P. Morgan Technical Document, $4^{\text {th }}$ Edition, J.P. Morgan, New York, 1996.

[52] R Development Core Team, A language and environment for statistical computing. R Foundation for Statistical Computing, Vienna, Austria, 2008. ISBN 3-90005107-0, URL http://www.R-project.org. 
[53] N. Shephard, in O.E. Barndorff-Nielsen, D.R. Cox and D.V. Hinkley (eds.), Statistical aspects of ARCH and stochastic volatility, Statistical Models in Econometrics, Finance and Other Fields, Chapman \& Hall, London, 1996, pp. 167.

[54] R. Smith, Estimating tails of probability distributions. Annals of Statististics, 15 (1987) 1174-1207.

[55] G. Stahl, Three cheers, Risk, 10 (1997) 67-69.

[56] J.L. Stein, The simultaneous determination of spot and futures prices, American Economic Review, 51 (1961) 1012-1025.

[57] G. Zumbauch, A Gentle Introduction to the RM 2006 Methodology, Riskmetrics Group, New York, 2007. 
Figure 1. Spot and futures daily returns

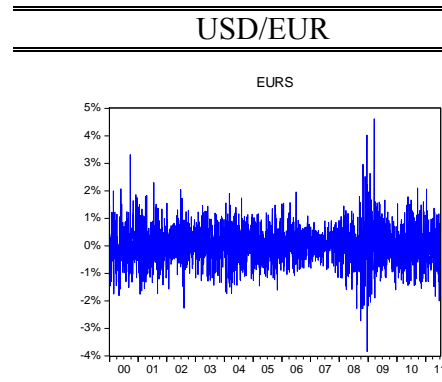
USD/GBP

USD/JPY
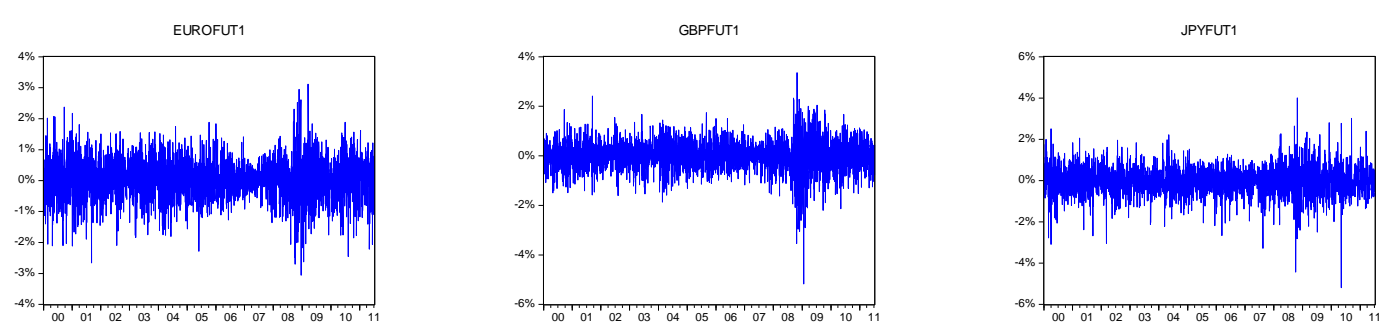

EUROFUT2
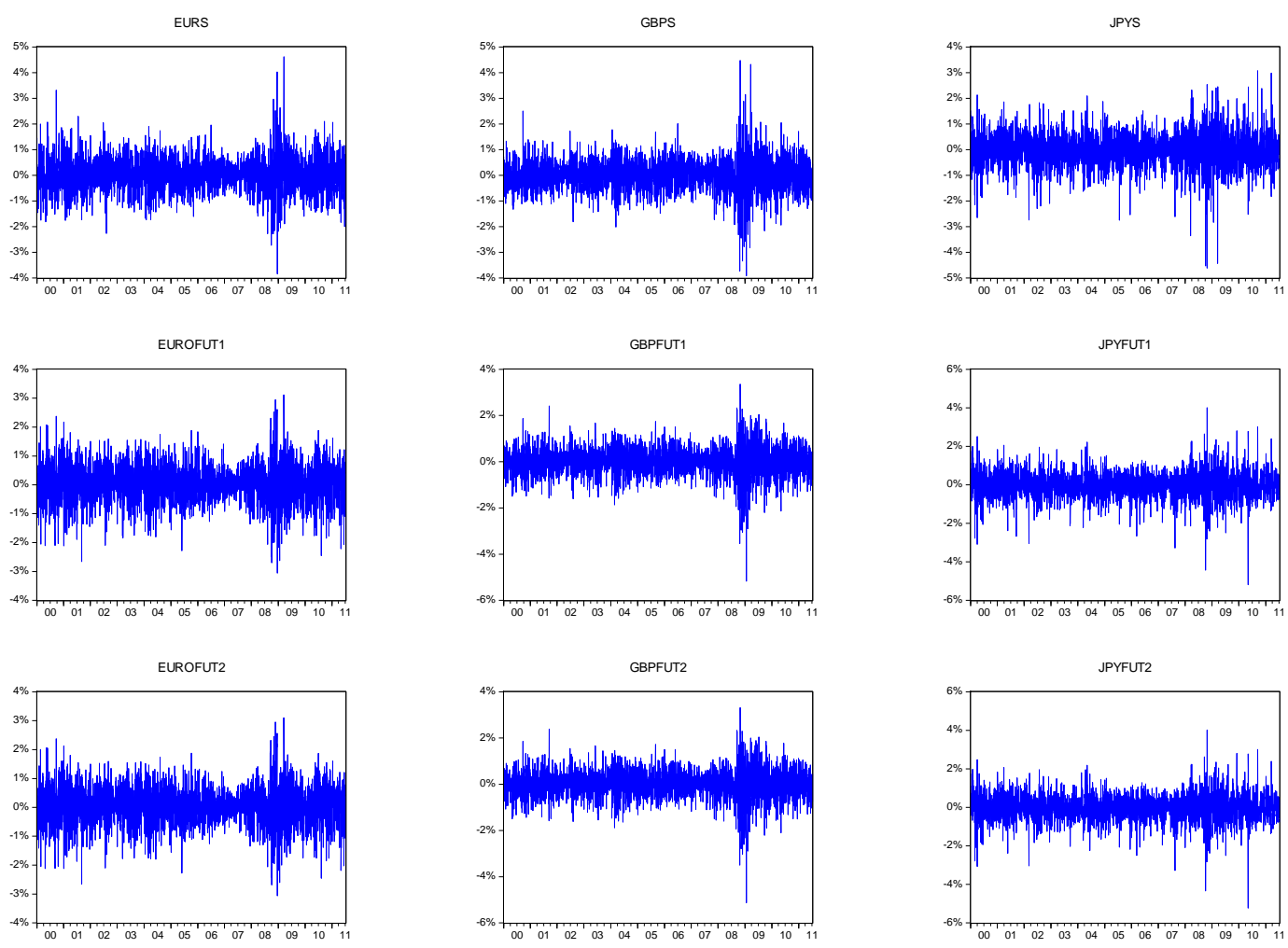
Figure 2. Estimated Conditional Volatilities of Returns

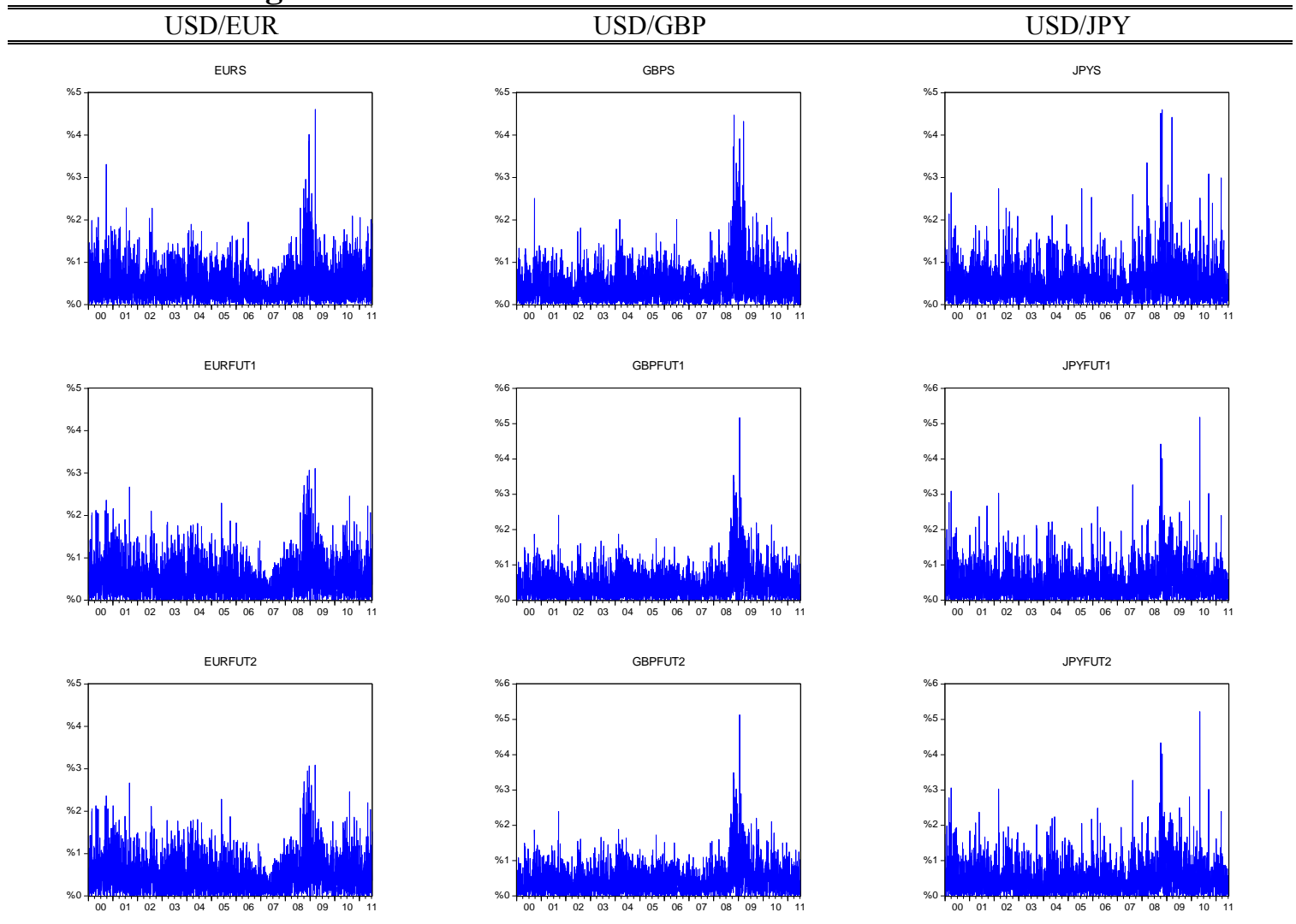

Figure 3. DCC Estimates

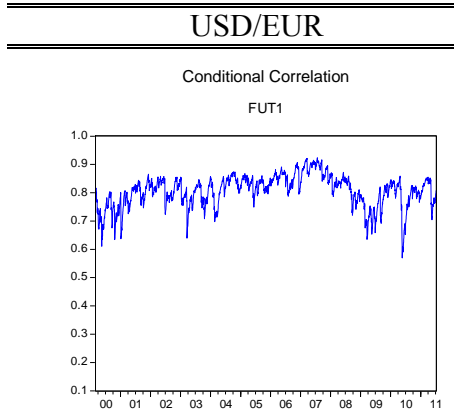

USD/GBP

$\mathrm{USD} / \mathrm{JPY}$

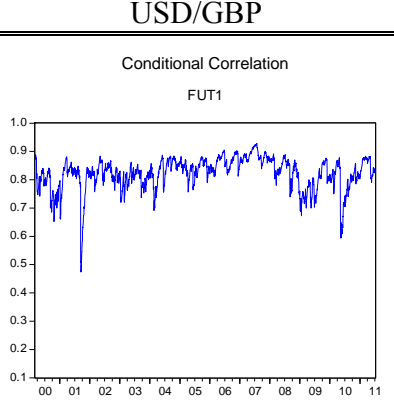

Conditional Correlation

Conditional Correlation

FUT2
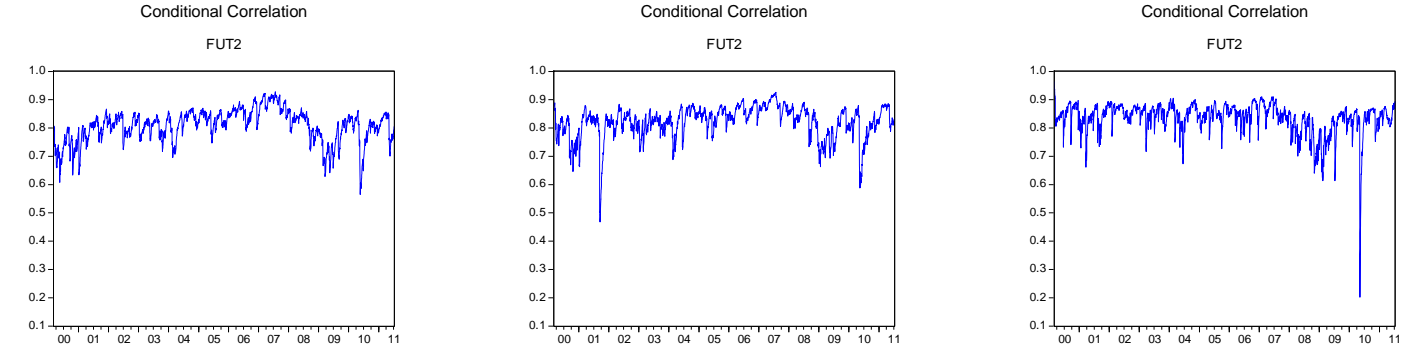
Figure 4. Optimal Hedge Ratios

USD/EUR

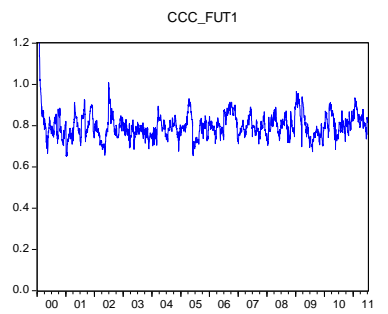

VARMA-AGARCH_FUT1

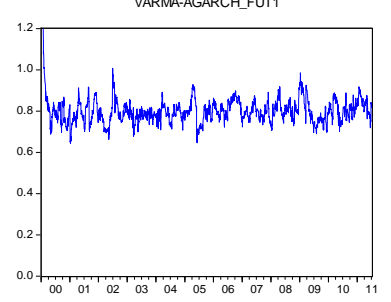

DCC_FUT1

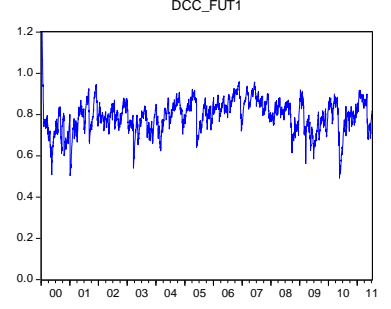

BEKK_FUT1

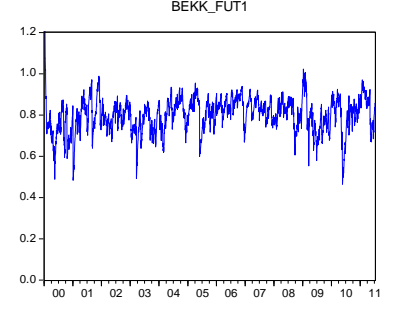

USD/GBP

USD/JPY

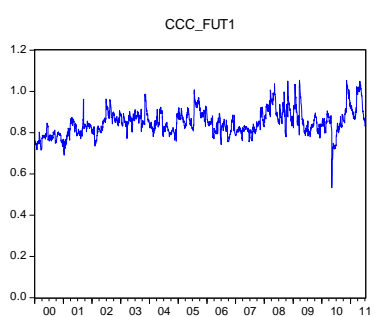

VARMAAGARCH_FUT1

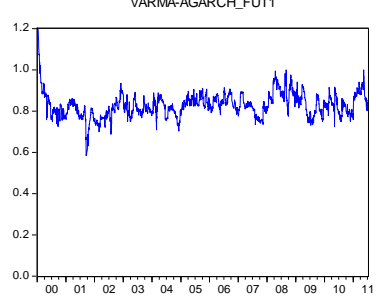

VARMA-AGARCH_FUT1

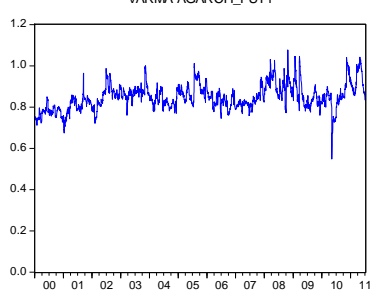

DCC_FUT

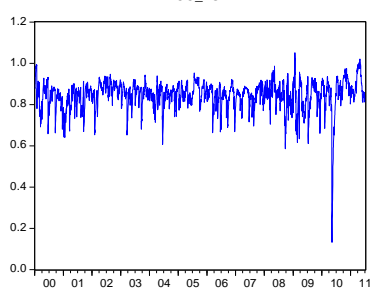

BEKK_FUT

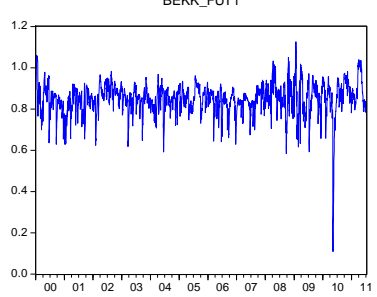


Table 1. EUR Descriptive Statistics

\begin{tabular}{|l|c|c|c|}
\hline Returns & EUROS & EUROFUT1 & EUROFUT2 \\
\hline \hline Mean & 0.0107 & 0.0101 & 0.0098 \\
Maximum & 4.6174 & 3.1184 & 3.1007 \\
Minimum & -3.8445 & -3.0568 & -3.0620 \\
Std. Dev. & 0.6485 & 0.6552 & 0.6532 \\
Skewness & 0.1477 & -0.0939 & -0.0962 \\
Kurtosis & 5.6389 & 4.3878 & 4.3556 \\
Jarque-Bera & 882.87 & 245.58 & 234.73 \\
\hline
\end{tabular}

Table 2. GPB Descriptive Statistics

\begin{tabular}{|l|r|r|r||}
\hline Returns & GBPS & GBPFUT1 & GBPFUT2 \\
\hline \hline Mean & -0.0007 & -0.0010 & -0.0011 \\
Maximum & 4.4745 & 3.3542 & 3.3147 \\
Minimum & -3.9182 & -5.1703 & -5.1326 \\
Std. Dev. & 0.6103 & 0.6010 & 0.6021 \\
Skewness & -0.0552 & -0.3793 & -0.3560 \\
Kurtosis & 7.3609 & 6.7628 & 6.5791 \\
Jarque-Bera & 2382.7 & 1844.9 & 1667.4 \\
\hline
\end{tabular}

Table 3. JPY Descriptive Statistics

\begin{tabular}{|l|c|c|c|}
\hline Returns & JPYS & JPYFUT1 & JPYFUT2 \\
\hline \hline Mean & -0.0077 & -0.0075 & -0.0070 \\
Maximum & 3.0770 & 4.0082 & 4.0187 \\
Minimum & -4.6098 & -5.1906 & -5.2289 \\
Std. Dev. & 0.6594 & 0.6642 & 0.6594 \\
Skewness & -0.4246 & -0.3285 & -0.3020 \\
Kurtosis & 6.5503 & 6.9307 & 6.9282 \\
Jarque-Bera & 1668.5 & 1988.5 & 1977.8 \\
\hline
\end{tabular}


Table 4. CCC Estimates

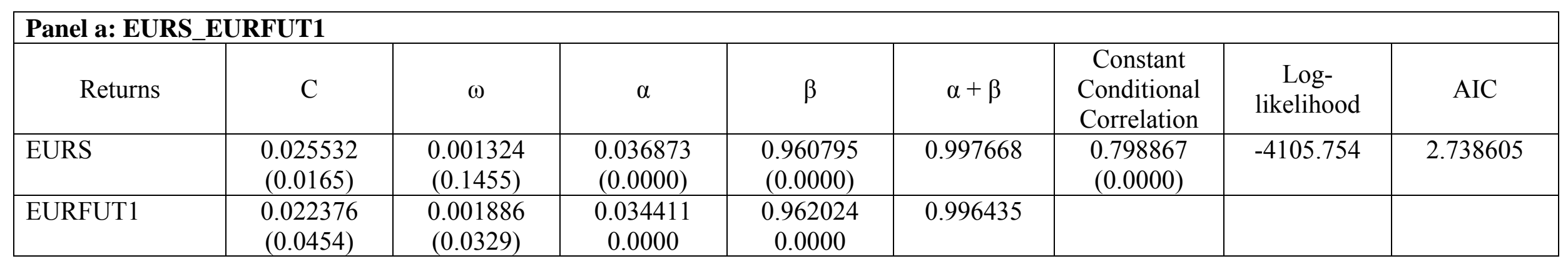

\begin{tabular}{|l|c|c|c|c|c|c|c|}
\hline \multicolumn{1}{|c|}{ Panel b: GBPS_GBPFUT1 } \\
\hline \multirow{2}{*}{ Returns } & $\mathrm{C}$ & $\omega$ & $\alpha$ & $\beta$ & $\alpha+\beta$ & $\begin{array}{c}\text { Constant } \\
\text { Conditional } \\
\text { Correlation }\end{array}$ & $\begin{array}{c}\text { Log- } \\
\text { likelihood }\end{array}$ \\
\hline GBPS & 0.014299 & 0.002229 & 0.030472 & 0.962650 & 0.993122 & 0.812791 & -3367.432 \\
& $(0.1479)$ & $(0.0086)$ & $(0.0000)$ & $(0.0000)$ & & $(0.0000)$ & \\
\hline GBPFUT1 & 0.012066 & 0.002608 & 0.028671 & 0.963302 & 0.991973 & & \\
& $(0.2202)$ & $(0.0055)$ & $(0.0000)$ & $(0.0000)$ & & \\
\hline
\end{tabular}

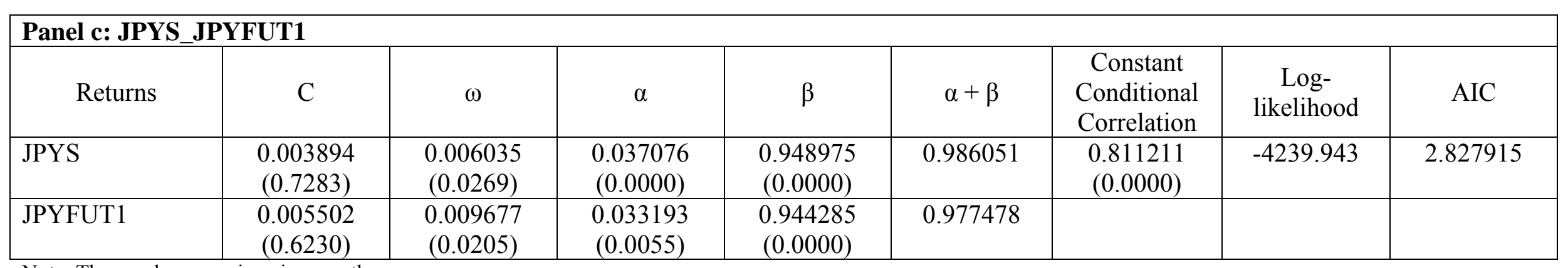

Note: The p-values are given in parentheses. 
Table 5. VARMA-AGARCH Estimates

\begin{tabular}{|c|c|c|c|c|c|c|c|c|c|}
\hline \multicolumn{10}{|c|}{ Panel a: EURS_EURFUT1 } \\
\hline Returns & $\mathrm{C}$ & $\omega$ & $\alpha$ & $\beta$ & $\gamma$ & $\alpha+\beta+\gamma$ & $\begin{array}{c}\text { Constant } \\
\text { Conditional } \\
\text { Correlation }\end{array}$ & $\begin{array}{c}\text { Log- } \\
\text { likelihood }\end{array}$ & AIC \\
\hline EURFUT1 & $\begin{array}{c}0.011699 \\
(0.2921)\end{array}$ & $\begin{array}{c}0.002113 \\
(0.0135)\end{array}$ & $\begin{array}{c}0.020336 \\
(0.0105)\end{array}$ & $\begin{array}{l}0.964626 \\
(0.0000)\end{array}$ & $\begin{array}{l}0.021366 \\
(0.0483)\end{array}$ & 1.006328 & & & \\
\hline
\end{tabular}

\begin{tabular}{|c|c|c|c|c|c|c|c|c|c|}
\hline \multicolumn{10}{|c|}{ Panel b: GBPS_GBPFUT1 } \\
\hline Returns & $\mathrm{C}$ & $\omega$ & $\alpha$ & $\beta$ & $\gamma$ & $\alpha+\beta+\gamma$ & $\begin{array}{c}\text { Constant } \\
\text { Conditional } \\
\text { Correlation } \\
\end{array}$ & $\begin{array}{c}\text { Log- } \\
\text { likelihood }\end{array}$ & AIC \\
\hline GBPFUT1 & $\begin{array}{r}0.001990 \\
(0.8368)\end{array}$ & $\begin{array}{c}0.002791 \\
(0.0021)\end{array}$ & $\begin{array}{r}0.016439 \\
(0.0301)\end{array}$ & $\begin{array}{c}0.964716 \\
(0.0000)\end{array}$ & $\begin{array}{c}0.020035 \\
(0.0644)\end{array}$ & 1.00119 & & & \\
\hline
\end{tabular}

\begin{tabular}{|c|c|c|c|c|c|c|c|c|c|}
\hline \multicolumn{10}{|c|}{ Panel c: JPYS_JPYFUT1 } \\
\hline Returns & $\mathrm{C}$ & $\omega$ & $\alpha$ & $\beta$ & $\gamma$ & $\alpha+\beta+\gamma$ & $\begin{array}{c}\text { Constant } \\
\text { Conditional } \\
\text { Correlation }\end{array}$ & $\begin{array}{c}\text { Log- } \\
\text { likelihood }\end{array}$ & AIC \\
\hline JPYS & $\begin{array}{c}0.004648 \\
(0.6808)\end{array}$ & $\begin{array}{c}0.006036 \\
(0.0315)\end{array}$ & $\begin{array}{c}0.038539 \\
(0.0006) \\
\end{array}$ & $\begin{array}{c}0.949630 \\
(0.0000) \\
\end{array}$ & $\begin{array}{c}-0.004651 \\
(0.7528)\end{array}$ & 0.983518 & $\begin{array}{c}0.811191 \\
(0.0000) \\
\end{array}$ & -4239.519 & 2.828964 \\
\hline JPYFUT1 & $\begin{array}{c}0.005544 \\
(0.6287)\end{array}$ & $\begin{array}{c}0.009533 \\
(0.0208)\end{array}$ & $\begin{array}{c}0.032053 \\
(0.0331)\end{array}$ & $\begin{array}{c}0.944463 \\
(0.0000)\end{array}$ & $\begin{array}{c}0.002810 \\
(0.8728)\end{array}$ & 0.979326 & & & \\
\hline
\end{tabular}

Note: The p-values are given in parentheses. 
Table 6. DCC Estimates

\begin{tabular}{|c|c|c|c|c|c|c|c|c|c|}
\hline \multicolumn{1}{|c|}{ Panel a: EURS_EURFUT1 } \\
\hline Returns & $\mathrm{C}$ & $\omega$ & $\alpha$ & $\beta$ & $\alpha+\beta$ & $\theta_{1}$ & $\theta_{2}$ & $\begin{array}{c}\text { Log- } \\
\text { likelihood }\end{array}$ & AIC \\
\hline EURS & 0.020377 & 0.004386 & 0.027374 & 0.961108 & 0.988482 & 0.023709 & 0.961618 & -4077.809 & 2.721337 \\
& $(0.0532)$ & $(0.0022)$ & $(0.0000)$ & $(0.0000)$ & & $(0.0000)$ & $(0.0000)$ & & \\
\hline EURFUT1 & 0.018240 & 0.006484 & 0.034551 & 0.949876 & 0.984427 & & & \\
& $(0.0910)$ & $(0.0002)$ & $(0.0000)$ & $(0.0000)$ & & & & \\
\end{tabular}

\begin{tabular}{|c|c|c|c|c|c|c|c|c|c|}
\hline \multicolumn{10}{|c|}{ Panel b: GBPS_GBPFUT1 } \\
\hline Returns & $\mathrm{C}$ & $\omega$ & $\alpha$ & $\beta$ & $\alpha+\beta$ & $\theta_{1}$ & $\theta_{2}$ & $\begin{array}{c}\text { Log- } \\
\text { likelihood }\end{array}$ & AIC \\
\hline GBPS & $\begin{array}{c}0.010971 \\
(0.2487)\end{array}$ & $\begin{array}{c}0.004841 \\
(0.0001)\end{array}$ & $\begin{array}{c}0.038697 \\
(0.0000)\end{array}$ & $\begin{array}{c}0.946627 \\
(0.0000)\end{array}$ & 0.985324 & $\begin{array}{c}0.041639 \\
(0.0000)\end{array}$ & $\begin{array}{c}0.936892 \\
(0.0000)\end{array}$ & -3303.009 & 2.205663 \\
\hline GBPFUT1 & $\begin{array}{c}0.009160 \\
(0.3353)\end{array}$ & $\begin{array}{c}0.006684 \\
(0.0001)\end{array}$ & $\begin{array}{c}0.049814 \\
(0.0000)\end{array}$ & $\begin{array}{c}0.930739 \\
(0.0000)\end{array}$ & 0.980553 & & & & \\
\hline
\end{tabular}

\begin{tabular}{|c|c|c|c|c|c|c|c|c|c|}
\hline \multicolumn{10}{|c|}{ Panel c: JPYS_JPYFUT1 } \\
\hline Returns & $\mathrm{C}$ & $\omega$ & $\alpha$ & $\beta$ & $\alpha+\beta$ & $\theta_{1}$ & $\theta_{2}$ & $\begin{array}{c}\text { Log- } \\
\text { likelihood }\end{array}$ & AIC \\
\hline JPYS & $\begin{array}{c}0.003990 \\
(0.7237)\end{array}$ & $\begin{array}{c}0.019263 \\
(0.0000)\end{array}$ & $\begin{array}{c}0.043614 \\
(0.0000)\end{array}$ & $\begin{array}{c}0.911911 \\
(0.0000)\end{array}$ & 0.955525 & $\begin{array}{c}0.050768 \\
(0.0000)\end{array}$ & $\begin{array}{c}0.862159 \\
(0.0000)\end{array}$ & -4173.424 & 2.784974 \\
\hline JPYFUT1 & $\begin{array}{c}0.005513 \\
(0.6364)\end{array}$ & $\begin{array}{c}0.048472 \\
(0.0000)\end{array}$ & $\begin{array}{c}0.069140 \\
(0.0001)\end{array}$ & $\begin{array}{c}0.824529 \\
(0.0000)\end{array}$ & 0.893669 & & & & \\
\hline
\end{tabular}

Note: The p-values are given in parentheses. 
Table 7. BEKK Estimates

\begin{tabular}{|c|c|c|c|c|c|c|c|c|c|}
\hline \multicolumn{10}{|c|}{ Panel a: EURS_EURFUT1 } \\
\hline Returns & $\mathrm{C}$ & \multicolumn{2}{|c|}{$\mathbf{C}_{\mathbf{H}}$} & \multicolumn{2}{|c|}{ A } & \multicolumn{2}{|c|}{ B } & $\begin{array}{c}\text { Log- } \\
\text { likelihood }\end{array}$ & AIC \\
\hline EURS & $\begin{array}{c}0.020559 \\
(0.0488)\end{array}$ & $\begin{array}{c}0.003112 \\
(0.0001)\end{array}$ & & $\begin{array}{c}0.163463 \\
(0.0000)\end{array}$ & 0.000000 & $\begin{array}{c}0.982880 \\
(0.0000)\end{array}$ & 0.000000 & -4101.786 & 2.735964 \\
\hline EURFUT1 & $\begin{array}{c}0.019446 \\
(0.0664)\end{array}$ & $\begin{array}{c}0.004368 \\
(0.0001)\end{array}$ & $\begin{array}{c}0.006801 \\
(0.0003)\end{array}$ & 0.000000 & $\begin{array}{c}0.213424 \\
(0.0000)\end{array}$ & 0.000000 & $\begin{array}{c}0.969448 \\
(0.0000)\end{array}$ & & \\
\hline
\end{tabular}

\begin{tabular}{|c|c|c|c|c|c|c|c|c|c|}
\hline \multicolumn{10}{|c|}{ Panel a: GBPS_GBPFUT1 } \\
\hline Returns & $\mathrm{C}$ & \multicolumn{2}{|c|}{$\mathbf{C}_{\mathbf{H}}$} & \multicolumn{2}{|c|}{ A } & \multicolumn{2}{|c|}{ B } & $\begin{array}{c}\text { Log- } \\
\text { likelihood }\end{array}$ & AIC \\
\hline GBPS & $\begin{array}{c}0.009175 \\
(0.3332)\end{array}$ & $\begin{array}{c}0.003862 \\
(0.0000)\end{array}$ & & $\begin{array}{c}0.195416 \\
(0.0000)\end{array}$ & 0.000000 & $\begin{array}{c}0.975276 \\
(0.0000)\end{array}$ & 0.000000 & -3315.017 & 2.212324 \\
\hline GBPFUT1 & $\begin{array}{r}0.007995 \\
(0.3992) \\
\end{array}$ & $\begin{array}{r}0.004889 \\
(0.0000) \\
\end{array}$ & $\begin{array}{c}0.007320 \\
(0.0001) \\
\end{array}$ & 0.000000 & $\begin{array}{c}0.238545 \\
(0.0000) \\
\end{array}$ & 0.000000 & $\begin{array}{c}0.960766 \\
(0.0000) \\
\end{array}$ & & \\
\hline
\end{tabular}

\begin{tabular}{|c|c|c|c|c|c|c|c|c|c|}
\hline \multicolumn{10}{|c|}{ Panel a: JPYS_JPYFUT1 } \\
\hline Returns & $\mathrm{C}$ & \multicolumn{2}{|c|}{$\mathbf{C}_{\mathbf{H}}$} & \multicolumn{2}{|c|}{ A } & \multicolumn{2}{|c|}{ B } & $\begin{array}{c}\text { Log- } \\
\text { likelihood }\end{array}$ & AIC \\
\hline JPYS & $\begin{array}{c}0.001488 \\
(0.8959) \\
\end{array}$ & $\begin{array}{c}0.022401 \\
(0.0000)\end{array}$ & & $\begin{array}{c}0.215503 \\
(0.0000)\end{array}$ & 0.000000 & $\begin{array}{c}0.950569 \\
(0.0000)\end{array}$ & 0.000000 & -4181.067 & 2.788730 \\
\hline JPYFUT1 & $\begin{array}{c}0.001963 \\
(0.8719)\end{array}$ & $\begin{array}{c}0.046133 \\
(0.0000)\end{array}$ & $\begin{array}{c}0.083282 \\
(0.0000)\end{array}$ & 0.000000 & $\begin{array}{r}0.298570 \\
(0.0000)\end{array}$ & 0.000000 & $\begin{array}{c}0.855350 \\
(0.0000)\end{array}$ & & \\
\hline
\end{tabular}

Note: The p-values are given in parentheses. 
Table 8A. Alternative hedging strategies (USD/EUR)

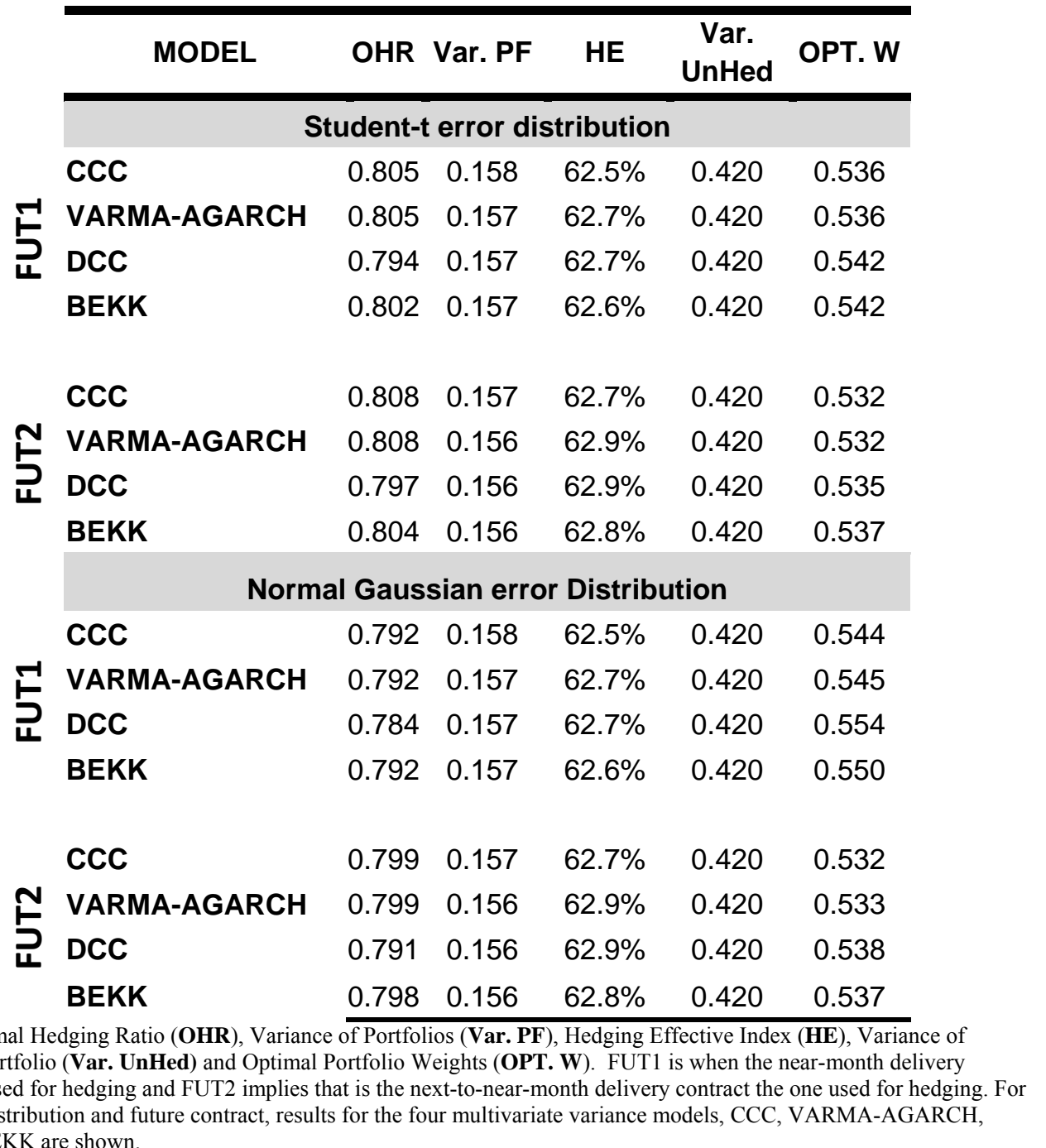


Table 8B. Alternative hedging strategies (USD/GBP)

\begin{tabular}{|c|c|c|c|c|c|c|}
\hline & MODEL & OHR & Var. PF & HE & $\begin{array}{l}\text { Var. } \\
\text { UnHed }\end{array}$ & OPT. W \\
\hline \multirow{5}{*}{ 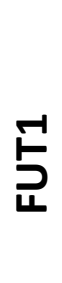 } & \multicolumn{6}{|c|}{ Student-t error distribution } \\
\hline & CCC & 0.829 & 0.126 & $66.2 \%$ & 0.372 & 0.496 \\
\hline & VARMA-AGARCH & 0.830 & 0.125 & $66.3 \%$ & 0.372 & 0.498 \\
\hline & DCC & 0.822 & 0.126 & $66.2 \%$ & 0.372 & 0.497 \\
\hline & BEKK & 0.826 & 0.126 & $66.2 \%$ & 0.372 & 0.490 \\
\hline \multirow{4}{*}{$\frac{N}{5}$} & CCC & 0.826 & 0.127 & $65.9 \%$ & 0.372 & 0.510 \\
\hline & VARMA-AGARCH & 0.826 & 0.126 & $66.1 \%$ & 0.372 & 0.512 \\
\hline & DCC & 0.817 & 0.127 & $65.9 \%$ & 0.372 & 0.511 \\
\hline & BEKK & 0.821 & 0.127 & $65.9 \%$ & 0.372 & 0.505 \\
\hline \multirow{5}{*}{ 돈 } & \multicolumn{6}{|c|}{ Normal Gaussian error Distribution } \\
\hline & CCC & 0.816 & 0.126 & $66.2 \%$ & 0.372 & 0.499 \\
\hline & VARMA-AGARCH & 0.815 & 0.125 & $66.3 \%$ & 0.372 & 0.503 \\
\hline & DCC & 0.818 & 0.126 & $66.1 \%$ & 0.372 & 0.500 \\
\hline & BEKK & 0.822 & 0.127 & $66.0 \%$ & 0.372 & 0.495 \\
\hline \multirow{4}{*}{$\underset{5}{5}$} & CcC & 0.812 & 0.127 & $65.9 \%$ & 0.372 & 0.510 \\
\hline & VARMA-AGARCH & 0.812 & 0.126 & $66.1 \%$ & 0.372 & 0.513 \\
\hline & $\mathrm{DCC}$ & 0.813 & 0.127 & $65.8 \%$ & 0.372 & 0.513 \\
\hline & BEKK & 0.817 & 0.128 & $65.7 \%$ & 0.372 & 0.508 \\
\hline
\end{tabular}

Notes: Optimal Hedging Ratio (OHR), Variance of Portfolios (Var. PF), Hedging Effective Index (HE), Variance of ungedged portfolio (Var. UnHed) and Optimal Portfolio Weights (OPT. W). FUT1 is when the near-month delivery contract is used for hedging and FUT2 implies that is the next-to-near-month delivery contract the one used for hedging. For each error distribution and future contract, results for the four multivariate variance models, CCC, VARMA-AGARCH, DCC and BEKK are shown. 
Table 8C. Alternative hedging strategies (USD/JPY)

\begin{tabular}{|c|c|c|c|c|c|c|}
\hline & MODEL & OHR & Var. PF & HE & $\begin{array}{c}\text { Var. } \\
\text { UnHed }\end{array}$ & OPT. W \\
\hline \multicolumn{7}{|c|}{ Student-t error distribution } \\
\hline \multirow{4}{*}{$\frac{\vec{E}}{\square}$} & $\mathrm{CCC}$ & 0.849 & 0.153 & $64.8 \%$ & 0.435 & 0.463 \\
\hline & VARMA-AGARCH & 0.849 & 0.153 & $64.8 \%$ & 0.435 & 0.464 \\
\hline & $\mathrm{DCC}$ & 0.845 & 0.153 & $64.8 \%$ & 0.435 & 0.475 \\
\hline & BEKK & 0.849 & 0.154 & $64.7 \%$ & 0.435 & 0.474 \\
\hline \multirow{4}{*}{$\underset{\mathbf{E}}{\mathbf{5}}$} & $\mathrm{ccc}$ & 0.853 & 0.154 & $64.6 \%$ & 0.435 & 0.450 \\
\hline & VARMA-AGARCH & 0.853 & 0.154 & $64.6 \%$ & 0.435 & 0.450 \\
\hline & $\mathrm{DCC}$ & 0.850 & 0.154 & $64.7 \%$ & 0.435 & 0.464 \\
\hline & BEKK & 0.854 & 0.154 & $64.6 \%$ & 0.435 & 0.468 \\
\hline \multicolumn{7}{|c|}{ Normal Gaussian error Distribution } \\
\hline \multirow{4}{*}{$\frac{H}{5}$} & $\mathrm{CCC}$ & 0.803 & 0.152 & $65.0 \%$ & 0.435 & 0.535 \\
\hline & VARMA-AGARCH & 0.802 & 0.152 & $65.0 \%$ & 0.435 & 0.537 \\
\hline & $\mathrm{DCC}$ & 0.812 & 0.153 & $64.8 \%$ & 0.435 & 0.566 \\
\hline & BEKK & 0.817 & 0.153 & $64.7 \%$ & 0.435 & 0.570 \\
\hline \multirow{4}{*}{$\underset{\mathbf{N}}{\mathbf{N}}$} & CCC & 0.810 & 0.153 & $64.8 \%$ & 0.435 & 0.514 \\
\hline & VARMA-AGARCH & 0.809 & 0.153 & $64.8 \%$ & 0.435 & 0.515 \\
\hline & $\mathrm{DCC}$ & 0.818 & 0.154 & $64.6 \%$ & 0.435 & 0.549 \\
\hline & BEKK & 0.823 & 0.154 & $64.5 \%$ & 0.435 & 0.555 \\
\hline
\end{tabular}


Table 9A. Correlations between OHRs (USD/EUR)

\begin{tabular}{|c|c|c|c|c|}
\hline & $\operatorname{CCC}$ & VARMA-AGARCH & DCC & BEKK \\
\hline \multicolumn{5}{|c|}{ Student-t error distribution } \\
\hline $\mathrm{CCC}$ & 1.00 & & & \\
\hline VARMA-AGARCH & 0.99 & 1.00 & & \\
\hline DCC & 0.66 & 0.65 & 1.00 & \\
\hline BEKK & 0.65 & 0.65 & 0.96 & 1.00 \\
\hline \multicolumn{5}{|c|}{ Normal Gaussian error Distribution } \\
\hline CCC & 1.00 & & & \\
\hline VARMA-AGARCH & 0.99 & 1.00 & & \\
\hline DCC & 0.66 & 0.65 & 1.00 & \\
\hline BEKK & 0.67 & 0.67 & 0.96 & 1.00 \\
\hline
\end{tabular}

Table 9B. Correlations between OHRs (USD/GBP)

\begin{tabular}{|c|c|c|c|c|}
\hline & CCC & VARMA-AGARCH & DCC & BEKK \\
\hline \multicolumn{5}{|c|}{ Student-t error distribution } \\
\hline $\operatorname{ccc}$ & 1.00 & 0.97 & 0.59 & 0.64 \\
\hline VARMA-AGARCH & 0.97 & 1.00 & 0.59 & 0.63 \\
\hline DCC & 0.59 & 0.59 & 1.00 & 0.97 \\
\hline BEKK & 0.64 & 0.63 & 0.97 & 1.00 \\
\hline \multicolumn{5}{|c|}{ Normal Gaussian error Distribution } \\
\hline $\operatorname{ccc}$ & 1.00 & & & \\
\hline VARMA-AGARCH & 0.97 & 1.00 & & \\
\hline DCC & 0.59 & 0.59 & 1.00 & \\
\hline BEKK & 0.64 & 0.62 & 0.97 & 1.00 \\
\hline
\end{tabular}


Table 9C. Correlations between OHRs (JPY/USD)

\begin{tabular}{|c|c|c|c|c|}
\hline & CCC & VARMA-AGARCH & DCC & BEKK \\
\hline \multicolumn{5}{|c|}{ Student-t error distribution } \\
\hline $\mathrm{CCC}$ & 1.00 & & & \\
\hline VARMA-AGARCH & 0.99 & 1.00 & & \\
\hline DCC & 0.55 & 0.55 & 1.00 & \\
\hline BEKK & 0.55 & 0.55 & 0.96 & 1.00 \\
\hline \multicolumn{5}{|c|}{ Normal Gaussian error Distribution } \\
\hline $\mathrm{CCC}$ & 1.00 & & & \\
\hline VARMA-AGARCH & 0.99 & 1.00 & & \\
\hline DCC & 0.59 & 0.59 & 1.00 & \\
\hline BEKK & 0.54 & 0.54 & 0.93 & 1.00 \\
\hline
\end{tabular}

